[FEB. 20, 1909.

the right hand shows loss of tactile sensation in the territory of the ulnar nerve on the dorsal surface and this loss extends two-thirds of the way up the forearm. There is very slight impairment of the senses of pain and temperature in the same nerve territory. The sense of posture and the stereognostic sense are preserved. There is slight tenderness of the first interosseous muscle and also of the paim of the hand and of the ring finger. The calves of the legs have a wasted appearance; the girth of the right is $11 \frac{1}{4}$ inches, of the left $11_{4}^{3}$ inches. There is slight cedema of the dorsum of each foot. Detailed examination of the right lower limb shows that the senses of pain, touch, and temperature are defective as high up as the knee, and on the outer aspect of the thigh. The foot and toes are tender on pressure, the calf slightly so. The movement of the toes is considerably reduced. The knee-jerks are difficult to obtain, though not absolutely lost." The evidence of neuritis was in the main similar in the limbs of the two sides. Repeated blood counts made about this time gave practically normal results. The fundi oculorum were likewise normal.

In the middle of February the patient had so far recovered that he was able to move about a little, but there was still well-marked muscular atrophy, particularly in the right hand; and the legs were still thin and weak. There was still tenderness of the muscles and the nerves, particularly in the right lower limb; and sensation was somewhat defective. There was some faint brown staining in the upper limbs and on the back, representing the old cutaneous eruption.

On March 19th there was still dull-red staining on the back of the trunk, which became brown on pressure. Both knee-jerks were present, though the right was sluggish. The girth of the right calf was $11 \frac{7}{8}$ inches and of the left $12 \frac{1}{2}$ inches.

On April 6th, the day before dismissal, the patient was practically well, but there was still a little tenderness on pressure of the right sole. The knee-jerks were both well marked. The only sensory defect discovered was a reduction of painful sensation in the right leg. There were still slight traces of the rash on the back of the trunk, and there was a little defect in the bulk of the muscles of the left hand.

Three features of this case are worthy of special note : (1) the Scandinavian origin of the patient ; (2) the fact that the disease seems to have originated while the patient was sailing off the shores of Great Britain ; and (3) the association of an erythematous eruption with the more familiar symptoms of beri-beri.

1. I know of no satisfactory explanation of the frequent occurrence of beri-beri among Scandinavian crews. The theory which has been proposed that the condition is really scurvy with peripheral neuritis is quite untenable in the present case not only because the diet was good but because the usual symptoms of scurvy were absent.

2. The beri-beri of temperate climates is met with chiefly, if not solely, in ships and asylums. It is rare in Europe, but it will be remembered that an outbreak occurred in the Richmond Asylum at Dublin some 15 years ago, and Manson and Daniels state that to their own knowledge the disease has originated in the Port of London among the crews of ships that had been in harbour for several months. ${ }^{1}$

3. The occurrence of this particular kind of erythematous eruption in such close association with the attack of beri-beri seems to be new to the literature. So high an authority as Manson remarks that beri-beri is not accompanied by an eruption. ${ }^{2}$ The late Mr. Conolly Norman, however, speaking of the Richmond Asylum cases, said that one patient had a series of herpetic patches which turned into bullæ and left little ulcers behind them, and that three or four cases were ushered in by an eruption which he could not distinguish from erythema nodosum. ${ }^{3}$

When one bears in mind the variety of diseases (including infections such as rheumatism, pneumonia, and polioencephalitis) which may be associated with an eruption of the exudative erythema type it is not surorising that a cutaneous eruption more or less akin to that type should be observed in an occasional case of beri-beri.

Glasgow.

1 Allbutt and Rolleston: System of Melicine, 1907, vol. ii., Part II., p. 616 .

\section{SOME NOTES ON THE INTERPELVI- ABDOMINAL AMPUTATION, WITH A REPORT OF THREE CASES.}

By J. HOGARTH PRINGLE, M.B. EdIN., F.R.C.S. EnG., SURGEON TO THE ROYAL INFIRMARY, GLASGOW.

I AM induced to publish the following notes on the subject of the interpelvi-abdominal amputation and to report the histories of three patients upon whom I performed this operation, partly because $I$ have not been able to find any record of similar cases in British literature, and partly becanse there are some points of great importance with reference to the operation, regarding which there is some difference of opinion. As a matter of fact, the operation does not appear to have been carried out more than a few times. I can only find references to 21 cases recorded.

The first case to be published seems to have been that of Jaboulay and some of the writers on the subject speak of the operation as "Jaboulay's operation," but actually the first operation of the kind was done by Billroth; his patient died and no report of the operation was ever published, and it is only known of through a verbal communication of Professor Berg, who was present at the operation, to Professor Girard, who recorded the first instance of a patient surviving the operation. In this case Girard made a re-amputation on account of the recurrence of a sarcoma in the pelvic bones following upon a former disarticulation at the hip-joint, the disease originally being in the upper third of the femur.

The indications for the operation are, in the first place, malignant neoplasms, and in the second place, certain infective processes involving the pelvic bones. It will be more satisfactory to speak of the two conditions separately. The only form of malignant growth which is in question is

Operations for Sarcoma.

\begin{tabular}{|c|c|c|c|c|}
\hline No. & Date. & Operator. & Result. & Reference. \\
\hline 1 & $\begin{array}{c}1889 \\
\text { or } \\
1891\end{array}$ & Billroth. & $\begin{array}{l}\text { Died after a few } \\
\text { hours. }\end{array}$ & $\begin{array}{l}\text { Savariaud, Revwe de Ohi- } \\
\text { rurgie, September, 1902. }\end{array}$ \\
\hline 2 & 1894 & Jaboulay. & Died next day. & $\begin{array}{c}\text { Lyon Médieale, } 1894, \\
\text { p. } 507 .\end{array}$ \\
\hline 3 & 1895 & Jaboulay. & $\begin{array}{c}\text { Died } 36 \text { hours } \\
\text { later. }\end{array}$ & Province Med., 1895 \\
\hline 4 & $?$ & Jaboulay. & Died 5 days later. & $\begin{array}{l}\text { Verbal communication to } \\
\text { Professor Girard. }\end{array}$ \\
\hline 5 & 1894 & Cacciopoli. & Died 3 hours later. & Ruforma Medica, 1894. \\
\hline 6 & 1895 & Gayet. & Died 1 hour later. & Province Med., 1894. \\
\hline 7 & 1895 & Girard. & Survived. & Revue de Chirurgie, 1895 ? \\
\hline 8 & 1897 & Girard. & Survived. & Revue de Chirurgie, 1898. \\
\hline 9 & 1899 & Faure. & $\begin{array}{l}\text { Died ; operation } \\
\text { abandoned. }\end{array}$ & Savariaud, loc. cit. \\
\hline 10 & 1899 & Freeman. & Survived. & Aunals of Surgery. \\
\hline 11 & 1900 & Nanu. & $\begin{array}{c}\text { Survived; died } \\
20 \text { th day ; gangrene. }\end{array}$ & Revue de Chirurgie, 1900 . \\
\hline 12 & 1900 & Salistcheff. & Survived. & $\begin{array}{l}\text { Archiv fürr Klinisehe } \\
\text { Chirurgie, } 1900 .\end{array}$ \\
\hline 13 & 1901 & Savariaud. & Died 2 hours later. & Revue de Chirurgie, 1902. \\
\hline 14 & 1901 & Gallet. & Died 1 hour later. & $\begin{array}{l}\text { Annales de la Société } \\
\text { Belge de Chirurgie, } 1901 .\end{array}$ \\
\hline 15 & 1902 & Morestin. & Died 9 hours later. & $\begin{array}{l}\text { Bulletins et Mémoires de la } \\
\text { Société Anatomique de } \\
\text { Paris, 1902. }\end{array}$ \\
\hline 16 & 1903 & $\begin{array}{l}\text { Keen and } \\
\text { Da Costa. }\end{array}$ & Died 33 hours later. & $\begin{array}{l}\text { International Clinies, } \\
\text { vol. iv., Series xiii. }\end{array}$ \\
\hline 17 & ? & Kadjan. & Died. & $\begin{array}{l}\text { Kocher's Operative Sur- } \\
\text { gery, fourth edition. }\end{array}$ \\
\hline 18 & $?$ & Kocher. & Died. & $\begin{array}{l}\text { Kocher's Operative Sur* } \\
\text { gery, fourth edition. }\end{array}$ \\
\hline
\end{tabular}

Operations for Tubereulosis.

\begin{tabular}{|c|c|c|c|c|}
\hline 19 & 1895 & Girard. & $\begin{array}{c}\text { Died } 50 \text { minutes } \\
\text { later. }\end{array}$ & Revue de Chirurgie, 1898. \\
\hline 20 & 1897 & $\begin{array}{l}\text { Barden- } \\
\text { heuer. }\end{array}$ & Survived. & $\begin{array}{l}\text { Verhandlungen der Deu } \\
\text { schen Gesellschaft } \\
\text { Chirurgie, 1897. }\end{array}$ \\
\hline & 1900 & Gallet. & Died 6 hours later. & Journal de Chirurgie, 19 \\
\hline
\end{tabular}


sarcoma, for all carcinomata of bone are secondary tumours in which therefore there can be no hope of eradicating the disease. Of the cases of sarcoma in which the question of this amputation can arise, there are those in which the highest part of the femur is affected and those in which the pelvic bone (usually the ilium) itself is the seat of the disease, or it may be the muscles, fascix, \&c., in the immediate proximity which are affected. And these structures, bone or soft tissues, may be affected either primarily, or secondarily after a former amputation of the limb for similar disease situated lower down. Of the 21 cases recorded and which are included in the accompanying table of Professor Keen, with two cases added, 18 were operated upon because of sarcoma, and it will be seen that only five patients survived the shock of the amputation.

Nanu's patient lived 20 days and died from sepsis. Each of Girard's patients lived about six months and died in consequence of recurrence of the disease. Both Freeman's and Salistscheff's patients were alive at the date of the reports being made. To these $I$ have to add the following notes of a case in which $I$ made this amputation on account of recurrence of a sarcoma after an amputation of the thigh rather below the level of the small trochanter.

CaSE 1.-The patient, a youth aged 18 years, was admitted to the Royal Infirmary, Glasgow, on Nov. 11th, 1906. He had first noticed stiffness at the left knee-joint seven weeks before this date. Later the joint became painful, the pain being felt in the popliteal space. There was no history of injury. There was slight thickening of the lower end of the left femur; the external condyle was rather softer than the internal and the knee-joint had a little fluid in its cavity. The transverse diameter of the condyles wasright, 10 centimetres; and left, 11.5 centimetres. On Nov. 14th amputation below the trochanters was performed, under the impression that the tumour was a central myeloid sarcoma, but dissection showed that it was sub-periosteal. Histologically it was a spindle-cell sarcoma. The wound healed aseptically and the patient went home on Dec. 12th. He remained well until November, 1907, when he began to have some vague pain in the stump. I saw him three weeks before his re-admission but could not discover any sign of a recurrence either in the stump or gluteal region or by rectal examination. I advised him to return in three weeks' time. He did so on Feb. 6th, 1908, when it was found that there was a quite small swelling to be palpated at the origin of the hamstring muscles, and he was readmitted on that date as he was most anxious to have a further operation. It was pointed out to him and his friends that any further operation likely to benefit him was associated with considerable risk but they were all willing to take it.

Examination of the patient failed to reveal any signs of further extension of the disease so on Feb. 12th, with spinal anæsthesia (stovaine), the interpelvi-abdominal amputation was carried out by making anterior and posterior skin flaps. The anterior flap began $1 \frac{1}{2}$ inches below the perineo-femoral fold over the adductor brevis muscle, running forwards about 2 inches below Poupart's ligament to the outer aspect of the thigh where it curved upwards to reach the iliac crest from 3 to 4 inches posterior to the anterior superior spine, thence along the crest to the synchondrosis. The origins of the abdominal muscles at the crest were divided, the peritoneum was pushed inwards, and the common iliac artery was divided between two ligatures. The posterior flap was then reflected; the incision for it joined that for the anterior flap about half way between the two iliac spines. The sacro-iliac synchondrosis was separated by dividing the ligaments from the external aspect. The horizontal ramus of the os pubis was divided with bone forceps immediately outside the origin of the left rectus abdominis and the ischial ramus immediately posterior to the attachment of the left crus of the penis. The patient was transfused with two pints of saline solution during the latter part of the operation. The abdominal muscles were sutured to the iliacus and the periosteum of the sacrum. The operation lasted 50 minutes in all. He made a good recovery and went home on March 30th, the wound being quite strong and with no tendency to hernial formation at all.

The patient was brought before a meeting of the Glasgow Medico-Chirurcical Society on May 1st, 1908 (the photograph was taken at this date). (Fig. 1.) On May 6th he had retention of urine. On the 10th the inability to pass urine persisting he had incontinence of fæces and was quite unable to move the right lower limb, and there was anæesthesia up to the fourth dorsal nerve on both sides. The same day a large bulla formed over the sacrum which had till then been quite free from any signs of trophic chango. On the 15th a bulla formed on the right external malleolus. No tumour could be palpated and the lungs showed no signs of any secondary deposit. On the 21st a swelling like a large gland was felt in the left iliac region. On the 30 th a small thickening was recognised over the lower end of the sternum.

The patient died on July 3rd, a tumour having formed on the ninth rib and another at the region of the symphysis pubis. At the post-mortem examination it was found that both lungs were studded with little nodules of the new growth. There were numerous small nodules along the

FrG. 1.

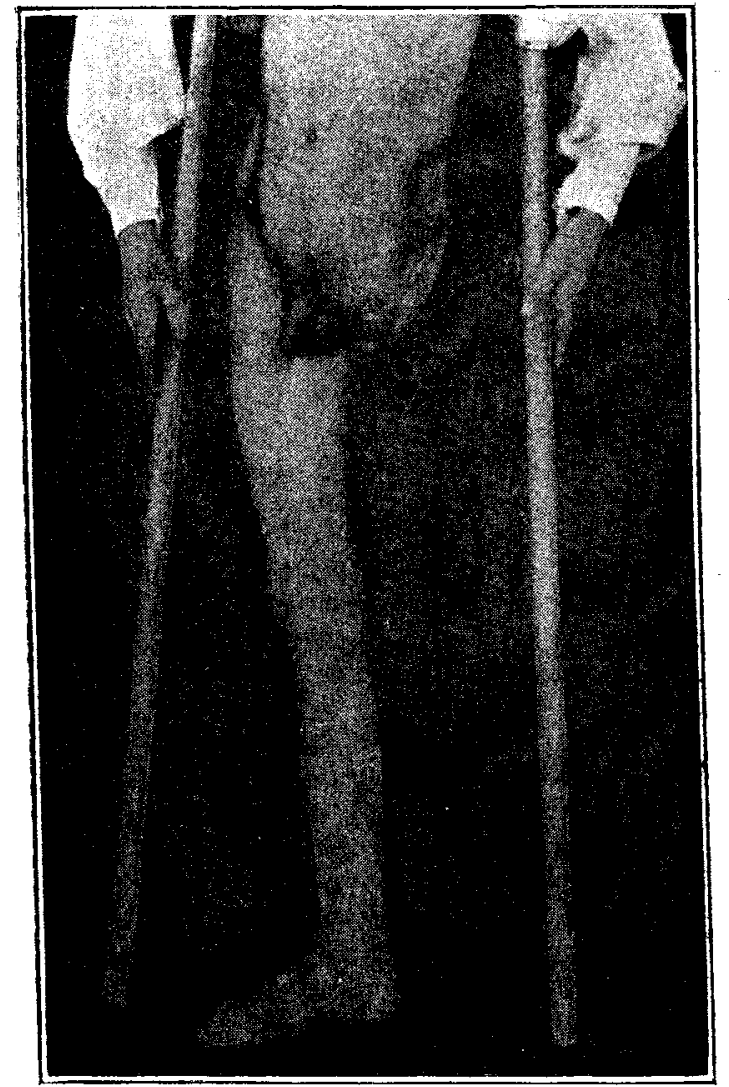

bodies of the vertebræ and the back of the sternum, and a mass about four inches in diameter in front and to the left of the bladder. On the dura mater of the spinal cord in the uppermost dorsal region there were two nodules causing compression of the cord.

This case makes the sixth survival from the shock of the operation in 19 patients operated upon, a mortality of $68 \cdot 3$ per cent.

Among the surgeons who have performed the operation some have come to the conclusion that the operation is not justified but with this opinion I am not able to agree. I quite recognise that every patient who has a sarcoma of the innominate bone is not suitable for the operation, nor is every patient who has a tumour at the upper extremity of the thigh. It appears to me that before undertaking the operation in any given case the surgeon should have some reasonable expectation of being able to remove the whole of the new growth; and the general condition of the patient must be such as to afford strong presumption of sufficient recuperative force to enable him to withstand the shock of the operation. It is further necessary to make the most thorough and complete examination possible for the purpose of determining whether the disease is local or has spread, a matter often of great difficulty, for the most careful examination will frequently fail to show that the disease has involved other parts. Where these conditions prevail, if a patient has the matter put before him regarding the incurability of the disease except by operation and the serious nature of this procedure, and still elects to have it done, it appears to me to be justifiable even though it may only prolong life for a few months.

Regarding the operation itself there are two points of 
some importance. First, as to the extent of the pelvic bone to be removed. Some of the surgeons who have carried out this operation have removed half the innominate bone from synchondrosis to symphysis while others have left the body of the pubic bone after dividing the rami. As the majority of the neoplasms which occur primarily in the innominate bone arise from the ilium it seems unlikely that by leaving that part of the os pubis which gives attachment to the rectus abdominis and the crus of the penis, the patient's chances are diminished, but if at the time of the operation there is any suspicion as to the condition of this portion of the bone it must be removed also.

Secondly, there is the question of tying the common iliac artery. The advisability of doing this is uncertain. I tied it in the case of my patient and after doing so, while cutting the anterior flap, made a small nick into the femoral artery a little below Poupart's ligament and I confess that I was surprised at the amount of blood which came away from the femoral through this small wound, as well as at the amount of bleeding that took place from the whole surface of the wound owing to the collateral circulation. Should I ever have occasion to do this operation again I think I would not waste time by exposing the vessel during the early stages of the operation. If left to a later stage, when it would naturally be divided in separating the pelvis from the trunk, the surgeon would be in a better position to decide whether to tie the common iliac artery itself or only its large terminals. It is probable that one would never have time to tie the parietal branches and to save the visceral branches of the internal iliac artery, and in some of the cases operated upon there would not have been any space in which to do this, though if this could be done it would certainly be desirable. The risk, however, of gangrene of the flaps after tying the common iliac, in my opinion, is slight provided the wound is aseptic. The flaps must in most cases be cut as one can best get covering for the wound. It seems that at least seven methods have been adopted and Keen describes six of them, including his own, and gives figures illustrating them. My flaps appear to differ from all those previously described, but they gave an excellent covering to the wound, and as they were of almost equal length their vascular supply was good. They most nearly resemble the flaps employed by Morestin in his case.

Rather different are the conditions under which one wonld have to do this operation for infections of the pelvic bone. The condition most likely to require the operation is tuberculous invasion of the bone, but it is just possible that actinomycosis might, and it has been recommended that the operation might be undertaken in certain cases of acute pyogenic osteomyelitis, but cases of these latter diseases requiring it must be extremely rare. There are, however, cases of tubercle infecting the innominate bone where the disease is so extensive that disarticulation at the hip even with extensive removal of parts of the pelvic bone at the same operation do not suffice. It is true that in some cases cure can be obtained in this way. In several instances I have disarticulated at the hip and removed the acetabulum and considerable portions of the ilium posterior to it with most satisfactory results, but in others, owing to sepsis, for practically all the cases in which this is necessary are suppurating at the time of operation, or owing to incomplete removal of all the disease, discharge continues and patients run down and die from exhaustion. So that it comes to be a question whether in these infected cases it would not be more advantageous (1) to perform the interpelvi-abdominal amputation at once, or (2) to disarticulate at the hip in the first place and later, at a second operation, to remove the affected half of the pelvis.

Several of the writers have dwelt on this point. It appears to me to be quite certain that a disarticulation at the hip in the first place, along with removal of as much of the diseased pelvis as is possible, to be followed by removal of the pelvic bone at a later date should this prove necessary owing to failure of the former operation to cure, is the best course to pursue. I did this eight years ago in the case of the patient whose notes are appended. A second patient was operated on in a very similar manner two years ago, but he unfortunately succumbed to the shock of the operation.

CASE 2.-.-The patient, a girl, aged ten years, was seen on Nov. 14th, 1899, with tuberculous disease of the left hipjoint, the thigh being flexed at the hip to almost a right angle. On Nov. 22nd the hip-joint was excised. The joint contained puriform fluid; the cartilage over the head of the femur and acetabulum was found destroyed. The child made good progress for a time but the wound became tuberculous. At the beginning of February, 1900, a profuse diarrhoea commenced; there were no albumin in the urine and no enlargement of the liver. About the middle of February some swelling was found in the left iliac fossa which increased and later fluctuation was detected. The patient was now extremely ill with undoubtedly a diffuse tuberculosis of the left half of the pelvis and I thought that the only possibility of prolonging her life was by removal of the left lower limb and left half of the pelvis, but to do this at the time did not seem likely to be followed by re. covery. I proposed, therefore, to amputate the limi and at a later date to remove the left pelvic bones. On March 5th the left limb was amputated at the hip and I gouged away the floor of the acetabulum along with a considerable part of the ilium, opening in this way into a large intrapelvic abscess with extremely fotid pus. The child's condition improved remarkably after this and the parents became unwilling that anything further should be done in the way cf operation. But the improvement was only very temporary; the diarrhcea was as bad as ever by the middle of April. The drainage through the pelvic wall became defective in consequence of granulations blocking the opening and the whole general condition of the patient was decidedly worse than it had been prior to the amputation, but I could not obtain the sanction of the parents for further operation until the end of May, and on June 1st I removed the left pelvic bones by opening up the former amputation wound and continuing it back along the iliac crest to the sacro-iliac synchondrosis. I sawed the ilium immediately outside the synchondrosis after detaching the abdominal muscles from the iliac crest and stripped off the tissues from the inner aspect of the pelvis with an elevator. The rami of the os pubis fractured off just outside the body of the bone, which was riddled with tubercle, and the body was therefore scraped completely away with a Volkmann's spoon.

FIG. 2.

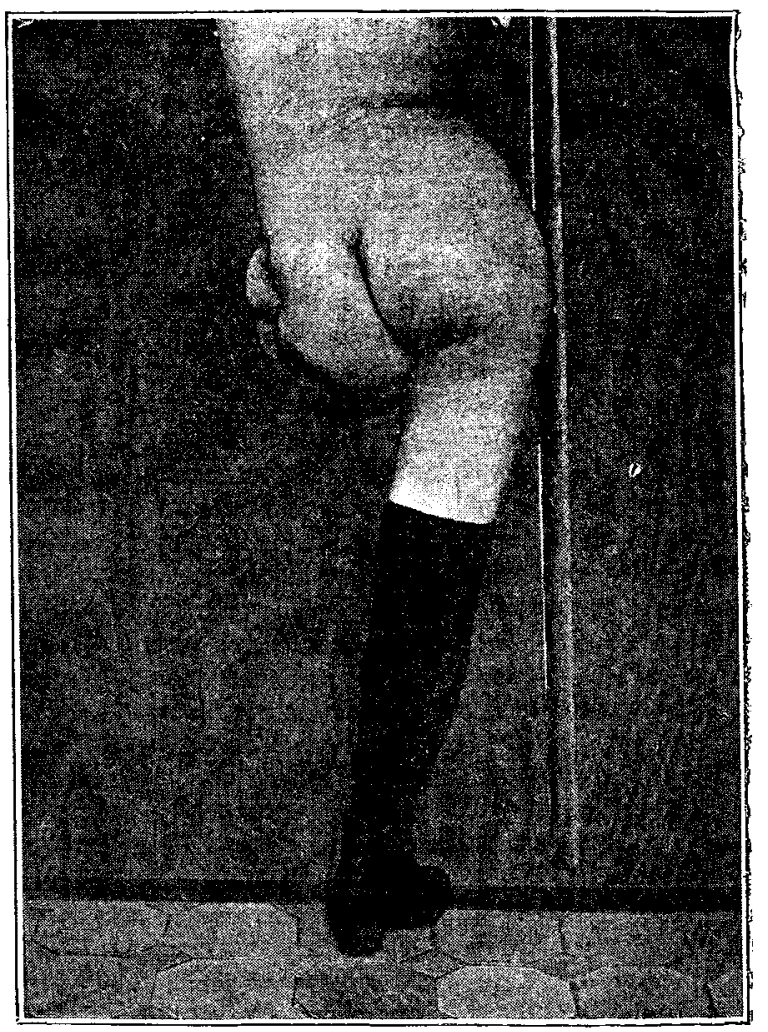

The patient made a good recovery and was last seen on Feb. 29th, 1908, when she was very well, fat, and plump. There was still a small sinus discharging a little pus at the posterior extremity of the wound at the crest of the ilium. No diarrhoea was present. She was photographed on this date (see Fig. 2). A very large mass of new bone has developed in the stump and which projects the soft parts, so that the appearance presented is rather like that of a disarticulation at the hip-joint.

CASE 3.-The patient was first admitted to the Royal 
Infirmary, Glasgow, in May, 1902, with an abscess over the left Poupart ligament which was attributed to a strain while working in a coal pit. This was opened and healed soundly. He was readmitted in July, 1904, with a large abscess in the left gluteal region which he had first noticed six weeks before admission. This was opened and he left the hospital in the following October well healed. He was again admitted in May, 1906, with deep sinuses at the sites of former abscesses. The left hip was flexed to a right angle and was fixed. The patient was very emaciated. Exarticulation at the left hip-joint was performed on May 14th. The pelvic bones were found to be extensively affected with tubercle and the acetabulum was bored through and a large abscess was opened inside the pelvis. The patient picked up fairly well and went out on June 28 th with the wound not completely healed. I anticipated that it might be necessary to remove the left pelvic bones but thought it advisable to wait a little longer before doing so to see if the drainage through the acetabulum would be sufficient.

The patient did not return until the following October. He was most anxious to have something further done. The scar of the amputation wound was tuberculous throughout and his general condition very poor. On Oct. 22 nd the left half of the pelvis was removed by incising along the amputation wound; the pubis was divided outside the origin of the left rectus abdominis. The body of the os pubis was removed with a Volkmann's spoon; the whole of the bone removed was riddled throughout with tubercle. He stood the operation better than I expected he might have done and in the evening seemed to be pretty well, but he collapsed later and died during the night. Nothing abnormal was found at the post-mortem examination in any of the internal organs; there were no amyloid disease and no tuberculous lesion.

I think that in future operations of this nature, where shock is the great danger to be avoided, we shall do best for wour patients by the use of spinal anæsthesia rather than by employing a general anæsthetic. I doubt whether my patient with the sarcoma would have got through had he had chloroform or ether. The question of amputating in two stages unfortunately cannot arise in those patients suffering from sarcoma.

Glasgow.

\section{A HISTORICAL INSTANCE OF THE ADAMS- STOKES SYNDROME DUE TO HEART-BLOCK. ${ }^{1}$}

By G. A. GIBSON, M.D., LL.D., F.R.C.P. EdIN., pHXsictay to THE ROYAL INFIRMARY, EDINBLRGH; AND

W. T. RITCHIE, M.D., F.R.C.P. EDIN.,

ASSISTANT PATHOLOGIST TO THE ROYAL INFIRMARY, EDINBURGH.

THE distinguished physician who forms the subject of the present paper had enjoyed during a long life excellent health; excepting that during his youth some suspicion had been aroused by the condition of the lungs which led to his spending a winter in Rome immediately after graduation. In 1899, being then 75 years old, he had a serious attack of influenza, and in the following year he retired from the positions which he occupied and came to reside in Edinburgh. Until his house was ready he lived in one of the suburbs and used to go backwards and forwards by train. In the month of August, 1900, when in the train he was suddenly attacked by unconsciousness and muscular rigidity. He was seen shortly afterwards by Professor John Wyllie and one of us (G. A. G.), and the condition was then found to be one of great prostration. Consciousness had returned but the patient was very dull and listless. The pulse at the wrist was only six per minute, the apex beat being the same, and there were no missed beats. The first sound was quite distinct, and was followed by a clear, ringing second sound, but between these were other feebler sounds (to be referred to later). In the course of a few hours the attack passed off and the pulse returned to its normal rate, between 60 and 70 , with complete disappearance of the nervous symptoms. A slight attack occurred in St. Paul's Cathedral, London, in October, 1900, and again in November, 1901, in his own 1 An abstract of a paper read before the Edinburgh Medico-Chirur
gical Society on Feb. 3rd, 1909 . house. A more serious and more prolonged seizure was experienced at Christmas, 1901, after which the normal was again reached. 'This condition of matters continued until July, 1902, when there was a sudden attack at church, with a pulse-rate of 16 and syncopal symptoms. In February, 1903, another seizure occurred in a tramway car, and on the same afternoon another attack came on in the street. The condition of the pulse during these attacks was not observed as he was not seen by his medical attendant until afterwards. During the same month he went to London and had one or two attacks of syncopal character, but the pulse was not observed to be below 40 at this time. Towards the end of the month he returned to Edinburgh and was found to be very faint; his pulse then was 40 . In March there were several attacks and the pulse fell to 32 per minute. During the rest of his life the pulse was never found to be above 34 or below 28 ; it was almost invariably 32 per minute. From March, 1903, until June, 1907, when he died, there was no syncopal or epileptiform attack. The patient manifested the keenest interest in his own condition and encouraged every inquiry into the nature of his affection. $\mathrm{He}$ was seen by many distinguished men from time to time, all of whom expressed their views in regard to the nature of the disease. From first to last there was a good deal of gastro-enteric catarrh, with dilatation of the hollow viscera, and considerable constipation. There never were any renal symptoms and the respiratory organs were wonderfully healthy, with the exception of slight impairment of the percussion sounds at the apices, accompanied by harsh breathing. After the cessation of the attacks of fainting and palpitation there never were any nervous symptoms. The patient slept well and every intellectual faculty was alert to the end of life. The circulatory organs presented features of the greatest interest. There was a distinct cervical venous pulse of the auricular type; the apex beat was slightly further to the left than usual; the impulse was well sustained and perfectly regular, with a usual rate of 32 ; the arteries were somewhat thickened but not in any way resistant; the condition of arterial pressure will be mentioned later. Percussion of the heart showed some enlargement, there being some dilatation with hypertrophy. On auscultation the first sound was replaced by a loud highpitched murmur, heard over the whole præcordia and particularly distinct at the apex; the second sound was loud and ringing, especially about the aortic cartilage. Following every second sound, and therefore preceding every systolic murmur, there could always be heard perfectly distinct sounds, usually two in number, which were by no means loud; these were undoubtedly caused by the pulsation of the auricles. Careful comparison of tracings taken from the jugular veins, the brachial and radial arteries, and the cardiac apex amply confirmed this impression, as there were always two, if not three, elevations made by the movements of the cervical veins for each ventricular impulse. It was perfectly clear that at first the case was one of partial or incomplete heart-block, as there was no absolute dissociation of ventricular and auricular movements, the ventricular pulsation being immediately preceded by an auricular impulse, although the interval between auricular and ventricular pulsation was not always exactly the same. In other words, the conductivity varied considerably. At a later period the condition seemed to pass into complete block. It was very interesting to find that the arterial pressure was extremely high during the systolic period, reaching as much as 230 and falling to 75 during the diastolic period. A comparison of all the phenomena with similar cases which have been under our care has shown us that it was a very interesting example of the Adams-Stokes syndrome due to heart-block. The termination came with dramatic suddenness, after the patient had passed through a period free from any disturbing symptoms. At the postmortem examination, which was expressly ordered by himself, the heart was found to be enlarged, measuring $17 \times 12 \times 11 \mathrm{~cm}$. The circumference of the heart $2 \mathrm{~cm}$. below the auriculo-ventricular groove was $37 \cdot 5 \mathrm{~cm}$. ; the subepicardial fat was abundant; the cavities were all dilated and hypertrophied; the hypertrophy of the trnia terminalis was well-marked. In the right ventricle there were patchy thickenings of the endocardium; the tricuspid valve showed some fibrous thickening but no calcification; the pulmonary orifice and artery were dilated. The segments of the mitral valve were thickened and 